\title{
Perspective
}

PERSPECTIVE Actualité en histoire de l'art

Comptes rendus | 2011

Wendy M. K. Shaw, Ottoman Painting: Reflections of Western Art from the Ottoman Empire to the Turkish Republic, Londres/New York, I. B. Tauris, 2011

\section{Zeynep Çelik}

\section{(2) OpenEdition}

\section{Journals}

Édition électronique

URL : http://journals.openedition.org/perspective/2665

DOI : $10.4000 /$ perspective. 2665

ISSN : 2269-7721

Éditeur

Institut national d'histoire de l'art

Référence électronique

Zeynep Çelik, «Wendy M. K. Shaw, Ottoman Painting: Reflections of Western Art from the Ottoman Empire to the Turkish Republic, Londres/New York, I. B. Tauris, 2011 », Perspective [En ligne], Comptes rendus, mis en ligne le 01 août 2013, consulté le 01 octobre 2020. URL : http://journals.openedition.org/ perspective/2665; DOI : https://doi.org/10.4000/perspective.2665 
Wendy M. K. Shaw, Ottoman Painting: Reflections of Western Art from the Ottoman Empire to the Turkish Republic, Londres/New York, I. B. Tauris, 2011

Zeynep Çelik

\section{RÉFÉRENCE}

Wendy M. K. Shaw, Ottoman Painting: Reflections of Western Art from the Ottoman Empire to the Turkish Republic, Londres/New York, I. B. Tauris, 2011. 
Dans son ouvrage bien documenté et rigoureusement théorique, Shaw s'intéresse à l'expression de la modernité dans l'art de la fin de l'Empire ottoman et des débuts de la République turque, s'appuyant sur des cas d'études qui comprennent aussi bien les décors peints de palais que des peintures de chevalet destinées à l'exposition publique. En interrogeant l'articulation de la production artistique avec des questions d'appartenance nationale, d'histoire et d'identité, et en mobilisant l'idée de la «traduction comme peinture» («translation as painting ), elle examine la production d'artistes ottomans à l'aune des courants artistiques européens. Elle défie les interprétations européocentriques, soutenant que ces

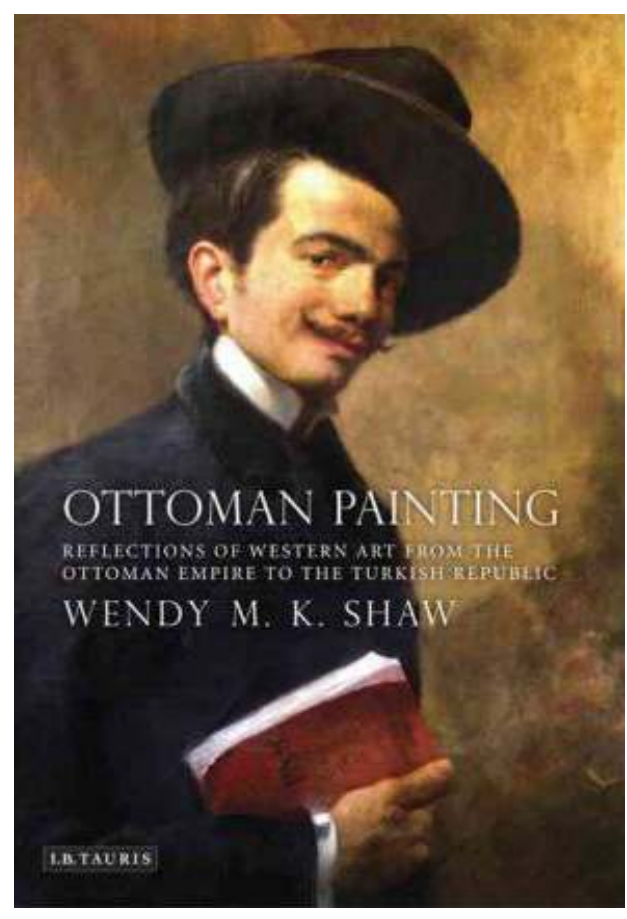
courants vibrants, loin d'imiter l'art occidental, ont constitué une nouvelle sorte d'avant-garde. Shaw complexifie ainsi le discours plus général sur l'art de la modernité et, ce faisant, intègre quantité d'artistes travaillant à cette époque de transition (dont des femmes) - ainsi que les contextes institutionnels dans lesquels ils évoluaient - au discours de l'histoire de l'art à la fin du $\mathrm{XIX}^{\mathrm{e}}$ siècle. Ses conclusions jettent une lumière nouvelle sur les préoccupations de la scène artistique turque actuelle. 